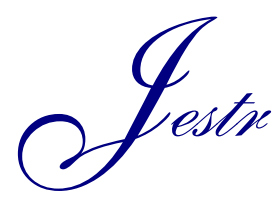

\title{
Stress Analysis of Perforated Casing in Shale Formation using Staged Finite Element Method
}

\author{
Mingtao Fan ${ }^{1, *}$, Jun Li ${ }^{1}$, Gonghui Liu ${ }^{1}$ and Mengxing Guo ${ }^{2}$ \\ ${ }^{I}$ College of petroleum Engineering, China University of Petroleum (Beijing), Beijing 102200, China \\ ${ }^{2}$ Faculty of Engineering, University of Ottawa, Ottawa K1N 6N5, Canada
}

Received 27 December 2016; Accepted 18 April 2017

\begin{abstract}
At present, collapse of perforated casing of some wells in shale formation during high-pressure fluid injection of massive hydraulic fracturing has been commonly observed. In order to accurately predict the stress state of the perforated casing during shale fracturing and identify the key factor affecting the perforated casing stress, a finite-element-method (FEM) mechanical model of perforated casing in anisotropic formation was established through staged finite element method (FEM). With this model, this study analysed the mechanism underlying the effects of injection fluid temperature, internal casing pressure, and cement properties on the stress of the perforated casing. Results show that thermal loading significantly affects the stress of perforated casing. The wellbore temperature decreases by $80{ }^{\circ} \mathrm{C}$, and the stress of perforated casing increases by $11.9 \%$ correspondingly. The reduction in internal casing pressure and appropriate increase in cement stiffness can greatly reduce the perforated casing stress. The appropriate Young's modulus of the cement for field operations ranges from $30 \mathrm{GPa}$ to $45 \mathrm{GPa}$. Variations in in-situ stress and pore pressure slightly influence the stress of perforated casing. Moreover, the stress of perforated casing decreases with increasing Young's modulus of formation. The stress of perforated casing reduces by $24 \%$ when the anisotropy index reaches 1.2 . The findings of this study can be used for the risk evaluation of the perforated casing failure during hydraulic fracturing, and also provide theoretical guidance for parameter optimization of field practices in cementing and hydraulic fracturing.
\end{abstract}

Keywords: Staged finite-element-method, Perforated casing, Anisotropy, Stress

\section{Introduction}

Shale reservoirs, featured by development of natural fractures and horizontal bedding planes, have extremely low porosity and permeability. Perforated casing completion of the horizontal wells plus multi-stage hydraulic fracturing is now the major technical means used in the exploitation of shale reservoirs.

In multi-stage fracturing, one or more main fractures are created in shale reservoirs, and meanwhile connectivity to natural fractures and bedding planes is generated by pumping diverting agents and large amounts of lowviscosity fluids at high pump rates through multi-stage completions. Consequently, the effective reservoir is broken up and complex fracture networks are formed, which lead to the $3 \mathrm{D}$ overall stimulation of shale reservoirs [1].

However, with the increasing shale gas production due to introduction of multi-stage hydraulic fracturing, downhole casing is subjected to complex stress state during the fracturing process characterized by high injection pressure, high pump rates and extensive stimulation scale. Meanwhile, as for the perforated casing completion of the horizontal wells, casing structural integrity is compromised and casing performances are impacted, particularly the collapse resistance, after the perforating charge penetrates the casing. Under the combined effects mentioned above, the deformation and collapse of the perforated casing frequently occur during volume hydraulic fracturing in shale formation, which further result in the failure of bridge plugs to reach their designed setting depths as well as difficulties in running subsequent completion tools. The failure could influence the performance of fracturing treatments, increase the operation cost and complexity, and introduce tremendous risks to following production operations [2-4]. Currently, the models to predict the perforated casing stress are mainly the 2D elasto-plastic model and 3D finite-element model. Given that the perforation of horizontal wells of shale reservoirs often requires to create multiple perforation holes in the casing, the 2D model neglects the interaction among perforations and is incapable of visually displaying the stress state of the perforated casing. Furthermore, unlike fracturing homogeneous formation, volume hydraulic fracturing in shale reservoirs is practiced in formation with strong anisotropy, and is accompanied by drastic variations in temperature, pressure and formation properties. Therefore it is a prior task to accurately calculate the stress state of the perforated casing in shale formation, so as to identify the primary factors that affect the perforated casing stress during volume hydraulic fracturing. Given the above-mentioned, this study established the $3 \mathrm{D}$ finite-element mechanical model of the perforated casing in anisotropic formation through staged finite element method (FEM). It aims to provide more accurate prediction of the stress state of perforated casing in shale formation during multi-stage 
fracturing, and further optimize the operation parameters of cementing jobs and fracturing treatments.

\section{State of the Art}

In the completion of horizontal wells of shale reservoirs, the casing need to be perforated [5]. It is shown in massive field practices that after the perforation completion, the created holes in the casing may damage the cylindrical consistency and affect tube strength [6,7]. The stress model of perforated casing has been highlighted for a long time. Tang [8] simplified the 3D mechanical model of the perforated casing into the planer model with a hole in a plate, and derived the theoretical formula of the collapse resistance factor of the perforated casing, on the basis of the theory of elasticity. Liu [9] on the basis of the elastic-plastic theory concerning a cylindrical shell with a hole, established the theoretical mechanical model of the perforated casing with a single perforation hole and developed a mathematical expression of the theoretical stress concentration factor. The stress distribution around the round hole was calculated, the position with the highest stress was identified, and a formula for effective stress concentration factor was proposed, in view of the sensitivity factor recommended according to materials and their specific application conditions. Nevertheless, the above analyses were all limited to the stress concentration induced by a single hole from the elastic-plastic point of view. The requirements for perforating multiple holes through the production casing in completion of shale gas horizontal wells impose certain limitations on the application of the 2D model to predict the stress of perforated casing in shale formation. While the FEM analysis can overcome the challenges aroused by the complex model, numerous parameters and long time span, and moreover allow real-time visualization of the casing deformation to elucidate the mechanical behavior of the perforated casing. Wang et al. established a 3D FEM model of perforated casing-cement sheath-formation by using nonlinear elastic-plastic theory, and analyzed the effects of perforation parameters on the perforated casing strength and also the resistance of the casing in the perforated interval to the non-uniform loading [10-13,15].

Previous studies show that although studies on the stress models of the perforated casing have been carried out by many scholars all around the world, the following limitations still exist: on one hand, the formation is often assumed to be isotropic and homogenous. Only few studies have focused on anisotropic formation. Moreover, in terms of the modelling, the conventional 3D FEM model considers casing, cement sheath, and formation as a whole, and applies internal casing pressure and in-situ stress directly to the inside and outside boundaries of the model, which ignores stress accumulation caused by rock excavation in drilling to hydraulic fracturing in the casing-cement-formation system, and is hence incapable of accurately predicting the stress of perforated casing in shale formation.

In terms of factors that affect the perforated casing stress, massive studies have also been conducted in an experimental or FEM. Wang et al. [10] and Ding et al. [11] used FEM to analyze the effects of perforation diameter, perforation density, and perforation phase angle on casing strength. Of these parameters, phasing angle has the greatest influence on casing strength, followed by perforation density and perforation diameter. Li et al. [14] reported that increasing the Young's modulus of cement strengthens the collapse resistance of the perforated casing. Wang et al. [16] concluded that non-uniform in-situ stress primarily affects the collapse of perforated casing. Qiu et al. [17] analyzed thermal stress distribution in perforated casing interval during thermal recovery of heavy oil and identified the thermal loading is the main factor that influences the stress of perforated casing. King, Hair, Schwind, Godfrey and Methven performed massive experimental studies and found that the strength weakening of the perforated casing is mainly affected by the perforation spacing between perforation holes [18-20]. Overall, narrow spacing can considerably decrease the casing strength.

In general, previous studies mostly concentrated on the thermal production of heavy oil and the effects of perforation parameters, casing materials, cementing quality, in-situ stress, and thermal loading on the perforated casing during the subsequent production stage of the oilfield development. However, factors affecting the stress of perforated casing in shale formation have been rarely investigated. Therefore, the effects of operation parameters in volume hydraulic fracturing and variations in fracturing mechanical environment on the stress of perforated casing in shale formation must be determined. Hence, this study, in view of limitations of previous studies, established a mechanical model of perforated casing through staged FEM based on the anisotropy of shale. The proposed model considered stress variation in the casing-cement-formation system from well construction to hydraulic fracturing. The model was used to analyze the effects of operational parameters (pump pressure and temperature) and fracturing mechanical environment (in-situ stress, properties of cement and formation) on the stress of perforated casing in shale formation. Results provide a theoretical basis for future perforation parameter optimization to decrease the operation blindness, improve the performance of fracturing treatments, and avoid damages to the perforated casing.

The remainder of this study is organized as follows. In Section 3, a perforated casing stress model of horizontal wells in anisotropic formation is set up; then in Section 4, the corresponding single-factor analysis and a case study are presented; finally the summary of this study is offered in Section 5, which lists the relevant conclusions.

\section{Methodology}

\subsection{Developing FEM model of the perforated casing in shale formation}

\subsubsection{Transversely isotropic model of shale formation}

From an engineering point of view, shale formation is considered as typical laminated formation, and accordingly can be regarded as transversely isotropic material. Then, shale formation can be described using five independent elastic parameters. The stress-strain constitutive equations are as follows [21]:

$$
\left\{\varepsilon^{\prime}\right\}=D^{-1}\left\{\sigma^{\prime}\right\}
$$

$$
D^{-1}=\left[\begin{array}{cccccc}
\frac{1}{E_{x}} & -\frac{v_{x y}}{E_{y}} & -\frac{v_{x z}}{E_{z}} & & & \\
-\frac{v_{x y}}{E_{y}} & \frac{1}{E_{y}} & -\frac{v_{y z}}{E_{z}} & & & \\
-\frac{v_{x z}}{E_{z}} & -\frac{v_{y z}}{E_{z}} & \frac{1}{E_{z}} & & & \\
& & & \frac{1}{G_{y z}} & & \\
& & & & \frac{1}{G_{z z}} & \\
& & & & & \frac{1}{G_{x y}}
\end{array}\right]
$$


Where $E_{x}=E_{z}$ refers to the transverse Young's modulus (parallel to the isotropic plane); $E_{y}$ is the longitudinal Young's modulus (perpendicular to the isotropic plane); $v_{x z}$ represents the transverse Poisson's ratio parallel to the isotropic plane; $v_{y z}=v_{x y}$ refers to the Poisson's ratio for loading perpendicular to the transverse plane. The shear modulus within the plane of isotropy, $X O Z$, is given by:

$$
G_{x z}=G_{h}=\frac{E_{h}}{2\left(1+v_{h}\right)}
$$

Where $G_{h}$ indicates the transverse shear modulus ( GPa ); $E_{h}$ is the transverse Young's modulus ( GPa ); $v_{h}$ is the transverse Poisson's ratio. Batugin and Nirenburg performed experiments and concluded the fifth longitudinal elastic constant, $G_{v}=G_{y z}=G_{x y}$ [22].

$$
G_{v}=G_{y z}=G_{x y}=\frac{E_{y} E_{z}}{E_{y}+E_{z}+2 v_{y z} E_{z}}
$$

3.1.2 Establishing the FEM coordinate system and determining mechanical parameters

Shale formation is featured by transverse anisotropy; hence, rock material orientation shall be defined after defining material parameters in establishing the numerical model.

A local coordinate system was set up, which, for simplicity, is consistent with the original coordinate system of the model (that is to say, $X-X^{\prime}, Y-Y^{\prime}$ and $Z-Z^{\prime}$ ). The $X Z$ - plane is the plane with isotropy (the transverse plane), and the $Y$ - axis is perpendicular to the transverse plane. The minimum horizontal principal stress is along the $X$ - axis, while the maximum horizontal principal stress, lies along the $Y$ - axis (Fig. 1).
The defined model parameters are listed below: Among the five engineering elastic parameters, the longitudinal Poisson's ratio and Young's modulus are respectively $v_{v}=0.223, E_{v}=40 \mathrm{GPa}$; the transverse Poisson's ratio and Young's modulus are $v_{h}=0.22, E_{h}=35 \mathrm{GPa} ; G_{h}$ and $G_{v}$ can be calculated using the Eq. (3) and Eq. (4). The permeability of shale formation is $0.1 \times 10^{-3} \mathrm{um}^{2}$; the porosity, $3 \%$; the fluid saturation, $100 \%$; the fluid density, $1 \mathrm{~g} / \mathrm{cm}^{3}$; the overburden pressure, $30 \mathrm{MPa}$; the minimum horizontal principal stress, $24 \mathrm{MPa}$; the maximum horizontal principal stress, $30 \mathrm{MPa}$; the fluid injection pressure, $80 \mathrm{MPa}$; the shut-in static pressure, $20 \mathrm{MPa}$; the initial reservoir temperature, $100{ }^{\circ} \mathrm{C}$. The geometric parameters, material characteristics, and thermodynamic properties are specifically shown in Tables 1 and 2 [23].

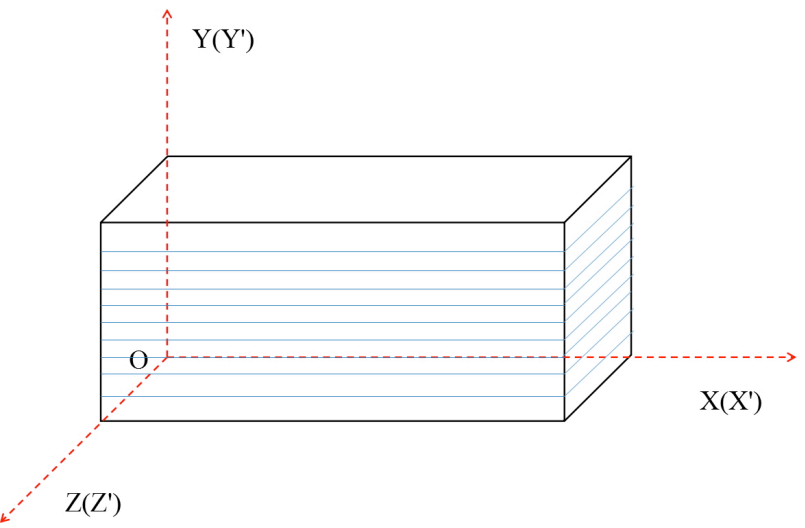

Fig. 1. Coordinate systems of laminar shale formation

Table1. Geometry parameters and material characteristics of the model

\begin{tabular}{c|c|c|c|c|c|c}
\hline Medium & $\begin{array}{c}\text { OD/ } \\
(\mathrm{mm})\end{array}$ & $\begin{array}{c}\text { ID/ } \\
(\mathrm{mm})\end{array}$ & $\begin{array}{c}\text { Young's Modulus/ } \\
(\mathrm{GPa})\end{array}$ & Poisson's Ratio & $\begin{array}{c}\text { Internal Friction Angle/ } \\
\left({ }^{\circ}\right)\end{array}$ & $\begin{array}{c}\text { Cohesion/ } \\
(\mathrm{MPa})\end{array}$ \\
\hline Casing & 139.7 & 131.98 & 210 & 0.3 & - \\
Cement sheath & 215.9 & 139.7 & 9 & 0.15 & 21.6 \\
Formation & 1270 & - & $E_{v}: 20$ & $v_{v}: 0.20$ & 30 \\
\end{tabular}

\begin{tabular}{|c|c|c|c|c|}
\hline Medium & $\begin{array}{l}\text { Density/ } \\
\left(\mathrm{kg} \cdot \mathrm{m}^{-3}\right)\end{array}$ & $\begin{array}{c}\text { Expansion Coefficient/ } \\
\left({ }^{\circ} \mathrm{C}^{-1}\right)\end{array}$ & $\begin{array}{l}\text { Specific Heat Capacity/ } \\
\qquad\left(\mathrm{J} \cdot \mathrm{kg}^{-1} \cdot{ }^{\circ} \mathrm{C}^{-1}\right)\end{array}$ & $\begin{array}{c}\text { Thermal Conductivity Coefficient/ } \\
\left(\mathrm{W} \cdot \mathrm{m}^{-1} \cdot{ }^{\circ} \mathrm{C}^{-1}\right)\end{array}$ \\
\hline Casing & 7800 & $1.22 \mathrm{e}^{-5}$ & 460 & 45 \\
\hline Cement sheath & 1800 & $1.05 \mathrm{e}^{-5}$ & 865 & 0.9 \\
\hline Formation & 2300 & $1.03 \mathrm{e}^{-5}$ & 896 & 2.2 \\
\hline
\end{tabular}

Tab. 2. Thermodynamic parameters of the model

\subsubsection{Establishment procedures of the FEM model}

1) Building the geometric model

Based on the three-dimensional consolidation theory, a 3D thick-walled cylinder model was built, with an external diameter of $3 \mathrm{~m}$ and the wellbore diameter of $0.1397 \mathrm{~m}$. The perforation tunnels, which were presented as small cylinders, were orthogonally well-connected to the wellbore, and had a symmetrically uniform distribution along the direction of the minimum horizontal principal stress. The perforation tunnels, which were presented as small cylinders, were orthogonally well-connected to the wellbore, and had a symmetrically uniform distribution along the direction of the minimum horizontal principal stress. The axes of perforation tunnels were perpendicular to the horizontal wellbore. The meshing required high precision, given the complexity of the geometric model and the partially interpenetrating wellbore and perforation tunnels that require removal. Therefore, the 
initial geometric model has been through multiple times of cutting, in order to refine the meshing of the wellbore and perforation holes.

\section{2) Initializing the stress of the cement sheath}

During oil and gas well cementing process, the static pressure imposed on the external surface of the casing and the internal surface of the formation by the cement slurry vanishes, and the elastic deformation as well as the initial compressive stress occurs in the cement sheath compressed by the casing and formation, after the cement solidifies. An assumption in this study is that the cement sheath would be under the hydrostatic state and subjected to no shear stress, after the cement solidification. In such cases, the initial stress state and the interface conditions cannot be determined if the loading and deformation histories are unknown. The reasonable stress initialization of the cement sheath was accomplished by the staged FEM. As the cement slurry hardens during the cementing process, it changes from liquid into solid and its mechanical properties also evolve. To simplify the calculation, the following assumption has been made in this study: in the analysis step of cementing, the cement instantly solidifies and changes into the cement sheath under the initial stress state, based on which further analyses are conducted. Compared with the models in previous studies, this model is more close to practical conditions.

\section{3) The staged FEM analysis}

The entire simulation can be divided into four stages, as shown in Fig. 2:

First, as shown in Fig. 2(a), the far-field horizontal principal stresses, overburden pressure, and pore pressure are applied to the formation and reach the equilibrium state.

Second, as shown in Fig. 2(b), the wellbore is removed from the model, and the static pressure of the drilling fluid column is imposed on the borehole wall to imitate the wellbore deformation and the corresponding stress state during drilling.

Third, as shown in Fig. 2(c), the cement sheath and casing are simultaneously introduced into the model, which leads to perfect matching between the outer boundary of the cement sheath and the deformed wellbore.

Fourth, pressures are applied to the interior wall of the casing to simulate the variations in downhole conditions during the subsequent operations. The interface elements based on the Coulomb's friction model, were used to capture the behavior of the interfaces of the cement sheath.

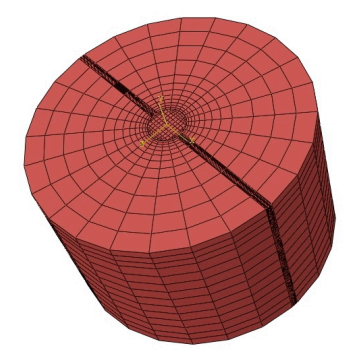

(a) The 1st step

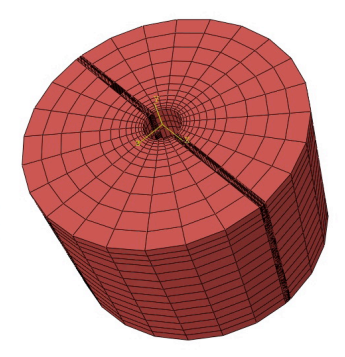

(b) The 2nd step

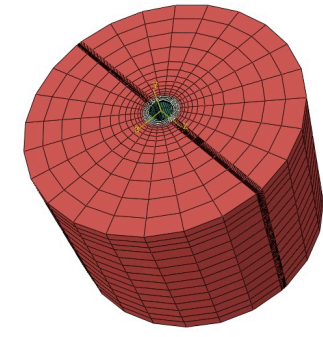

(c) The 3rd step

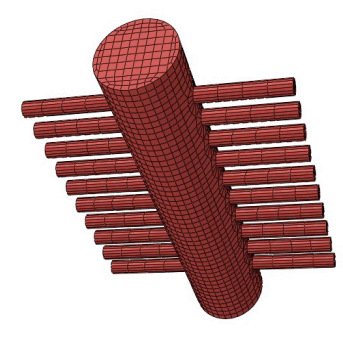

(d) Removed parts
Fig. 2. Schematic diagrams of the staged FEM analysis

\subsection{Failure criteria for the perforated casing}

According to the Von Mises yield criteria, the von Mises stress under the triaxial stress state at any point of the casing can be given as:

$\sigma_{e}=\left[\left(\sigma_{1}-\sigma_{2}\right)^{2}+\left(\sigma_{2}-\sigma_{3}\right)^{2}+\left(\sigma_{3}-\sigma_{1}\right)^{2}\right]^{1 / 2}$

Where $\sigma_{1}, \sigma_{2}$ and $\sigma_{3}$ are respectively the three principal stresses imposed on the casing; $\sigma_{e}$ is the Von Mises stress of the casing under the triaxial stress state.

The casing starts to yield, as the Von Mises stress satisfies Eq. (6):

$\sigma_{e} \geqslant \sigma_{y}$

Where $\sigma_{y}$ is the yield strength of the casing [24].

\section{Results and Discussion}

The lithology of formation, the distribution of in-situ stress, and operation parameters all affect the stress variation of the perforated casing during operation. Accordingly, focused discussion was made on the effects of the aforementioned factors on the stress of perforated casing.

\subsection{Effect of temperature variation on the stress of perforated casing}

Based on preliminary calculation, the wellbore temperature vs. time is shown in Fig. 3. During the multi-stage hydraulic fracturing process, the wellbore temperature fluctuates and gradually decreases. The maximum wellbore temperature is $80^{\circ} \mathrm{C}$ in the injection process, while the largest temperature difference found in the shut-in period is $40^{\circ} \mathrm{C}$. Therefore, it is safe to say that the effect of temperature variation on the perforated casing stress cannot be ignored.

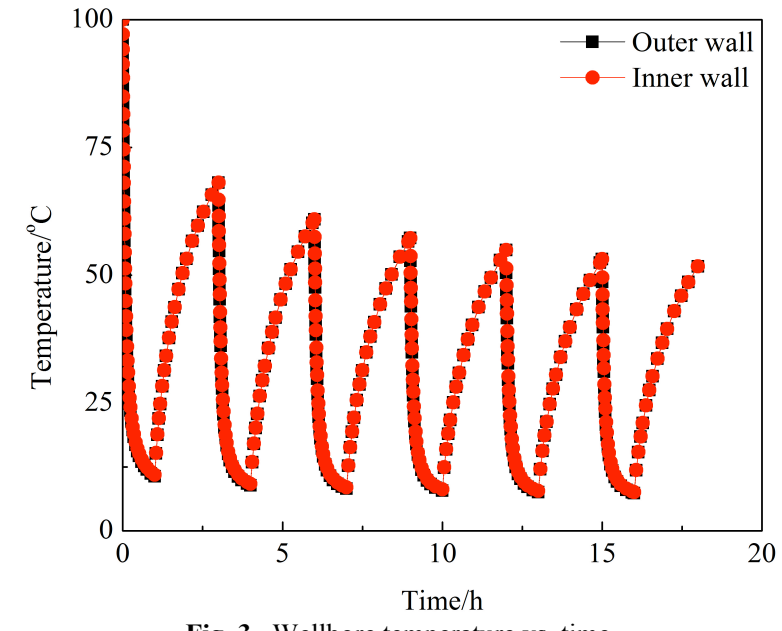

Fig. 3. Wellbore temperature vs. time 
Conventional models often absorb the thermal transfer through the internal surface of the casing, but neglect the transfer through perforation tunnels and consequent influences on the temperature field distribution of the casing-cement-formation system, in terms of the effects of temperature on the perforated casing. Two thermal loading patterns were performed in this study, as shown in Fig. 4(a), in the first pattern, the thermal loading was only imposed on the internal surface of the casing, and Fig. 4(b), in the second pattern, the thermal loading was applied to both internal casing surface and connected perforation tunnels.

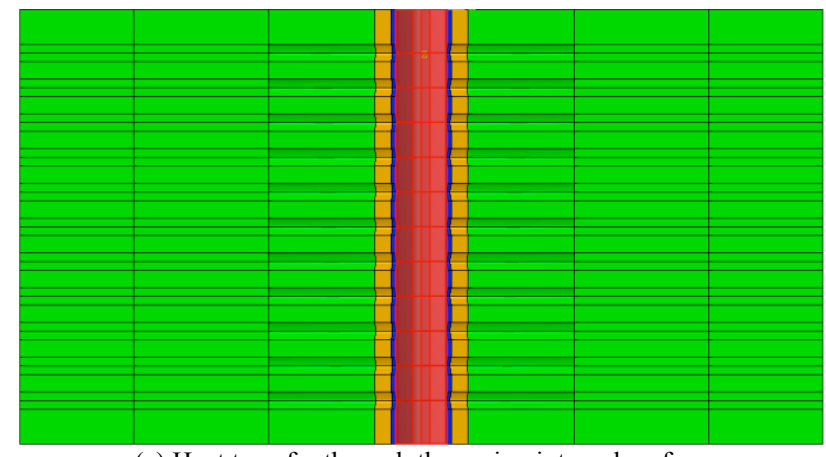

(a) Heat transfer through the casing internal surface

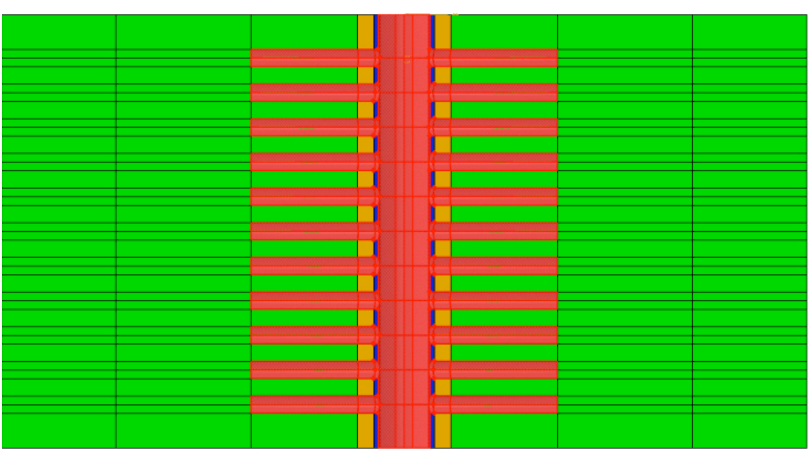

(b) Heat transfer through the casing internal surface plus the perforation

Fig. 4. Defined heat transfer patterns

As shown in Fig. 5(b), where the temperature field from the inside wall of casing to the formation is uniform, provided that only the temperature of the insider wall of casing is taken into consideration, and the lowest temperature is found to reduce to $20^{\circ} \mathrm{C}$. However, when the heat transfer through the perforation tunnel is considered, the temperature of the perforated casing declines and cement sheath grows, with the lowest temperature reaching $9{ }^{\circ} \mathrm{C}$ (Fig. 5(c)), and the near-wellbore temperature changes obviously. This leads to the conclusion that the wellbore temperature field distribution predicted by conventional models has certain errors, compared with the reality, and hence affects the accuracy of the simulation to the effects of wellbore temperature variation on the stress of perforated casing.

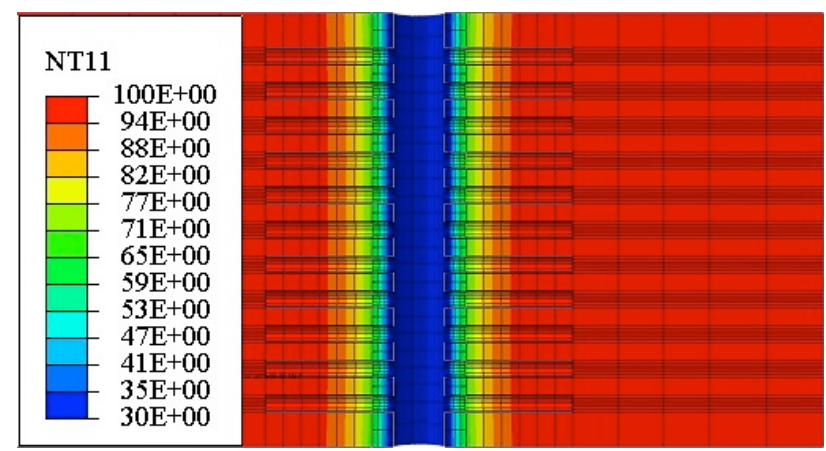

(a) The initial stage ( NT11: C )

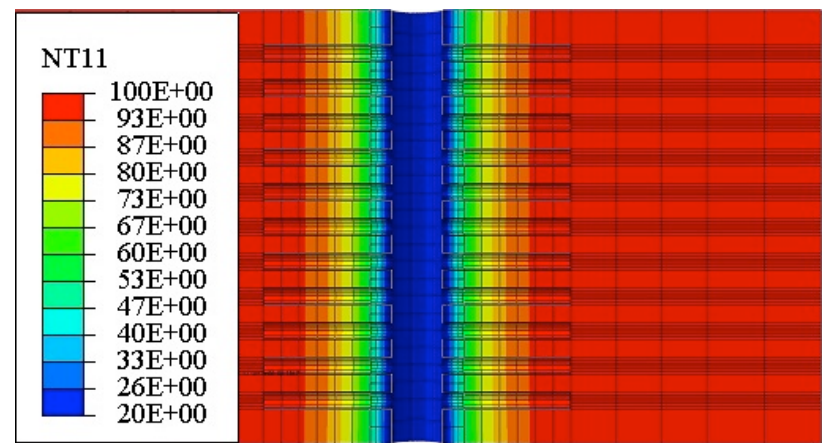

(b) Results of heat transfer only through the casing internal surface

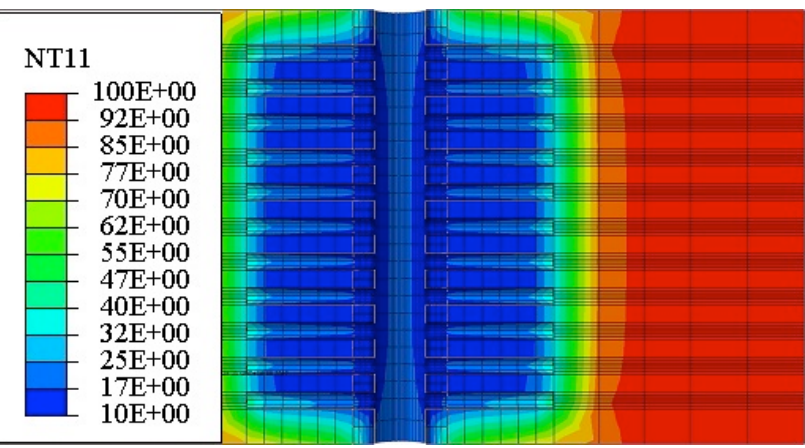

(c) Results of heat transfer through the casing internal surface plus the perforation tunnels

Fig. 5. Temperature field distribution of the casing-cement-formation system, with varied heat transfer areas

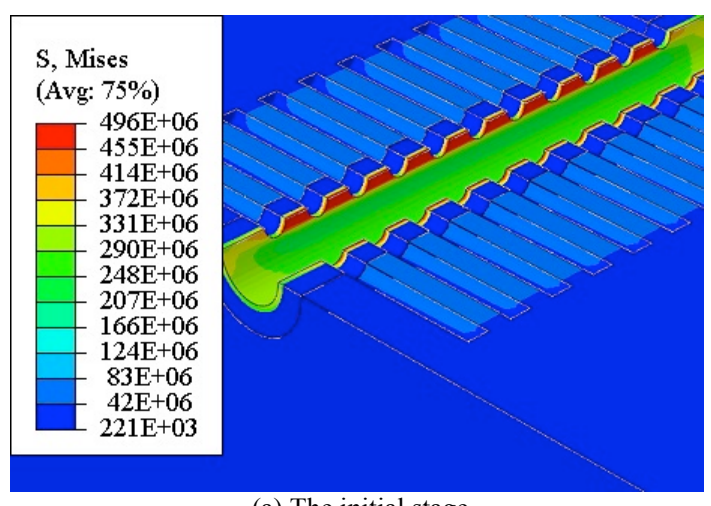

(a) The initial stage 


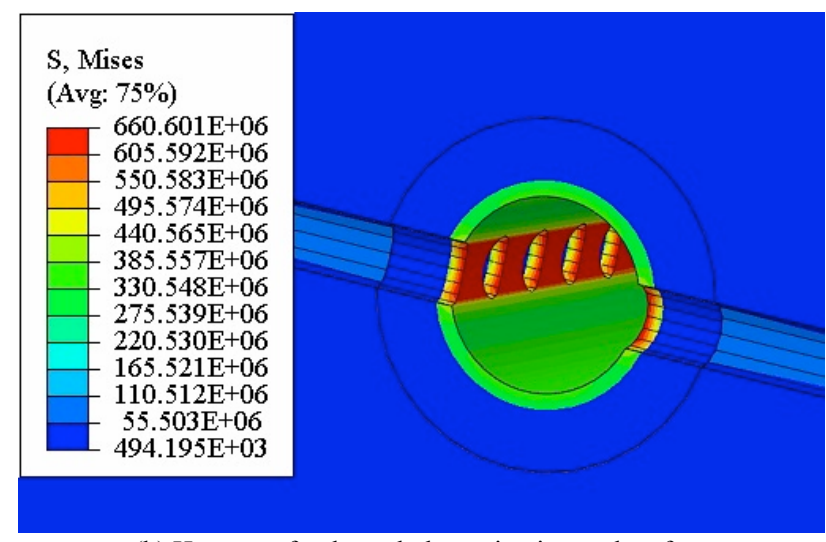

(b) Heat transfer through the casing internal surface

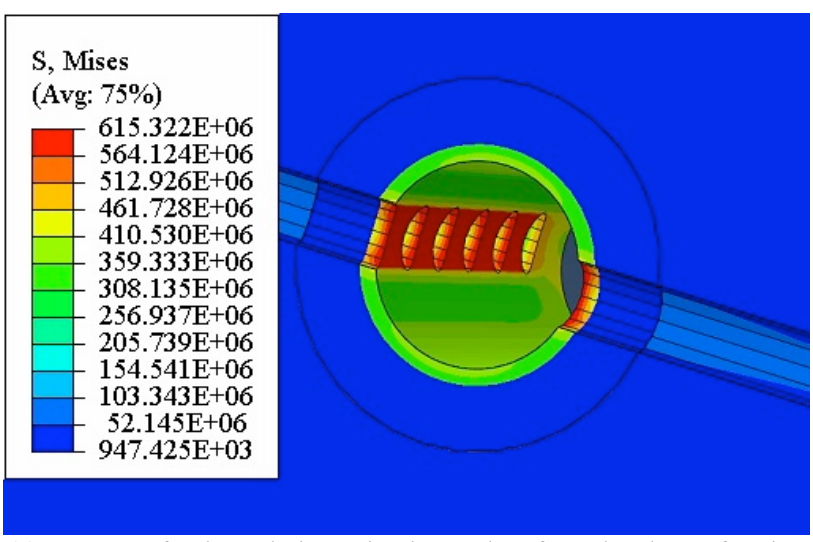

(c) Heat transfer through the casing internal surface plus the perforation tunnels

Fig. 6. Variation patterns of the stress of perforated casing, under varied heat transfer patterns

The effects of wellbore temperature drop on the stress of the perforated casing concerning the two thermal loading patterns are shown in Fig. 6. It is illustrated that the perforated casing stress continuously increases with the falling temperature, respectively by $33 \%$ (Fig. 6(b)) and $23 \%$ (Fig. 6(c)) in the two heat transfer patterns. The conventional heat transfer setting overestimates the increased degree of the stress of perforated casing, and inevitably affects the determination of some subsequent operation parameters.

\subsection{Effect of in-situ stress on the stress of perforated casing}

The local in-situ stress field can be altered by fluid injection in fracturing operations of adjacent wells [25-27], so that it is necessary to understand how the reservoir stress distribution affects the perforated casing stress in the targeted wellbore interval prior to the stimulation of the reservoir. The changing patterns of the stress of perforated casing with the in-situ stress of two types of models are presented in Fig. 7. With high-pressure injection of fluids, the gap of the stress of perforated casing between the conventional model and the proposed new model gradually expands with the constantly growing in-situ stress. Therefore it is seen that a higher initial in-situ stress of formation leads to a higher tendency of conventional models to underestimate the stress of perforated casing, during the high-pressure injection, which causes unfavorable influences on the design of operation parameters.

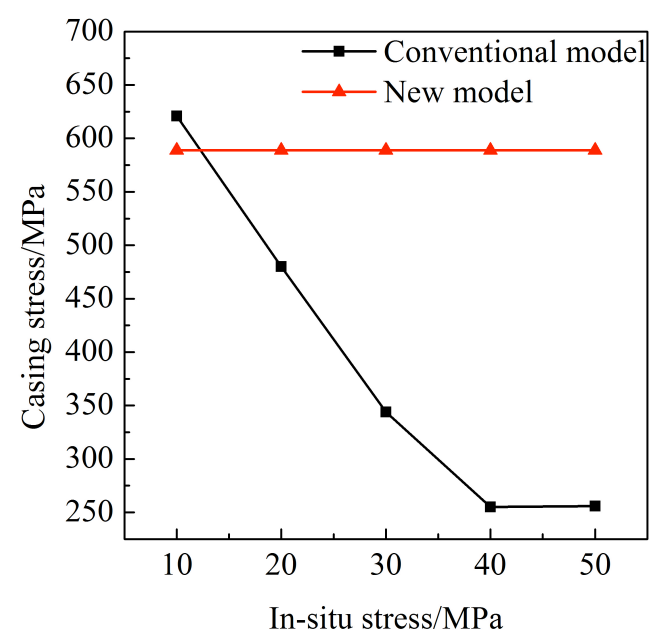

Fig. 7. Stress of perforated casing vs. In-situ stress

\subsection{Effect of pore pressure on the stress of perforated casing}

Fracturing fluid flow into the formation during multi-stage fracturing locally alters pore pressure in the near-wellbore region. Fig. 8 shows the pattern of influences of pore pressure altered by fracturing operations in adjacent wells on the perforated casing stress of the perforated wellbore interval of the target well. It is shown that as the pore pressure rises, the perforated casing stress calculated using the conventional model grows slowly, but is still far below that predicted by the new model.

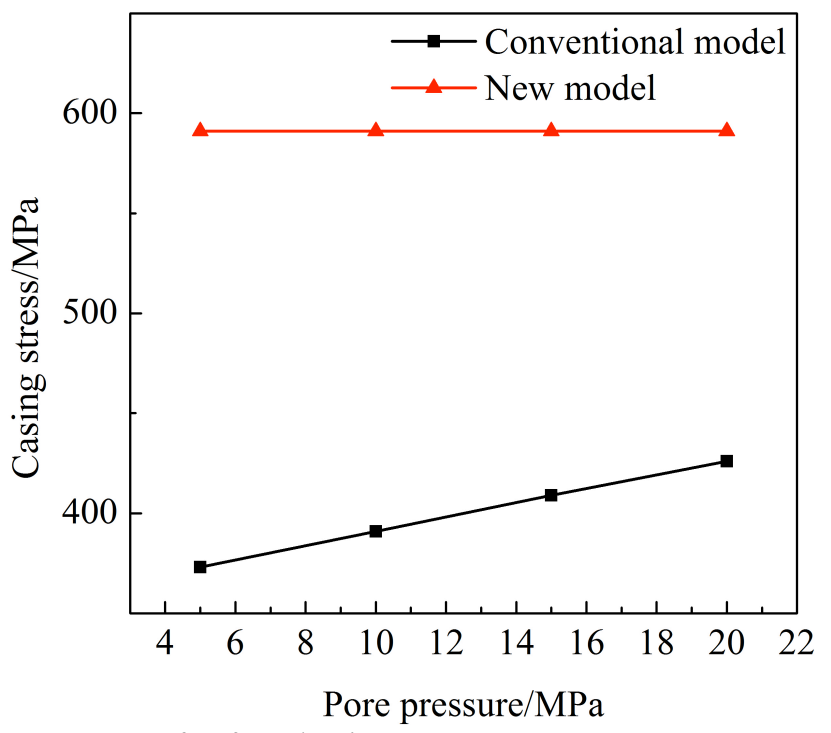

Fig. 8. Stress of perforated casing vs. Pore pressure

\subsection{Effect of formation properties on the stress of perforated casing}

The anisotropy index in this study was defined as $k=E_{h} / E_{v}$, namely the ratio of the Young's modulus of shale formation along the bedding planes to that Young's modulus perpendicular to the bedding planes. The index $k$ implies the degree of anisotropy, with higher $k$ value indicating stronger anisotropy. As shown in Fig. 9, the stress of perforated casing during high-pressure fluid injection in a conventional model grows with the strengthening anisotropy of rock properties. However, as the anisotropy of the Young's modulus intensifies in the staged FEM model, the stress of perforated casing slowly decreases before sharply declining. The trend is a result of anisotropy of Young's modulus changing the near-wellbore stress distribution, 
which exaggerates the in-situ stress heterogeneity and leads to decreases in the stress of perforated casing during fluid injection. It is also shown that with low degrees of anisotropy, the perforated casing stress calculated by the conventional model is severely underestimated, while it is considerably overrated in cases of anisotropy indexes over 1.2. The overvalued stress of perforated casing results in conservative operation parameters of following procedures, which affect hydraulic fracturing performance.

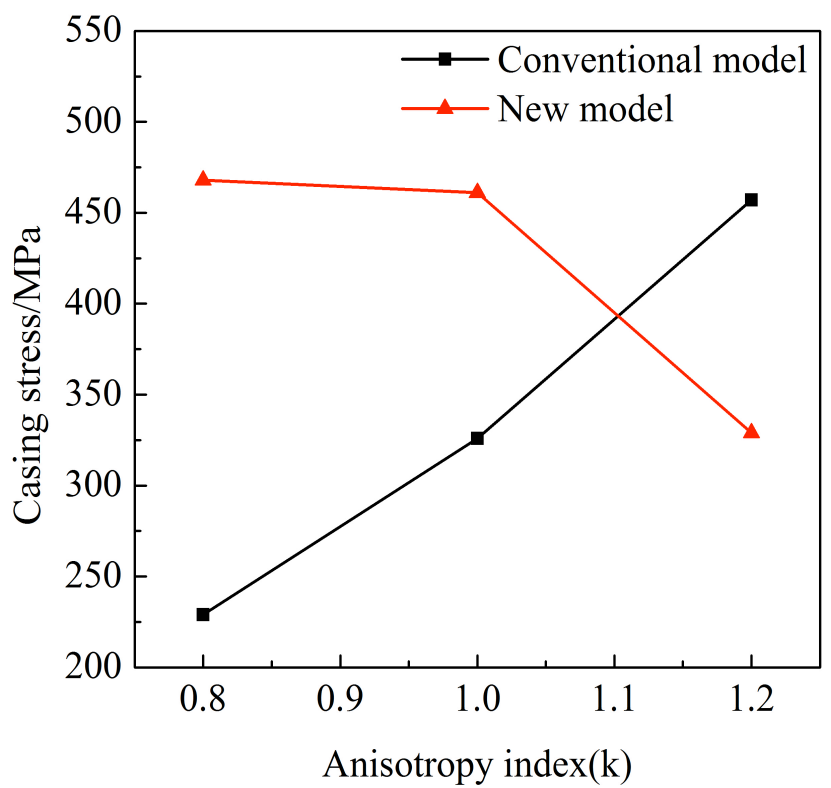

Fig. 9. Stress of perforated casing vs. Anisotropy index (k)

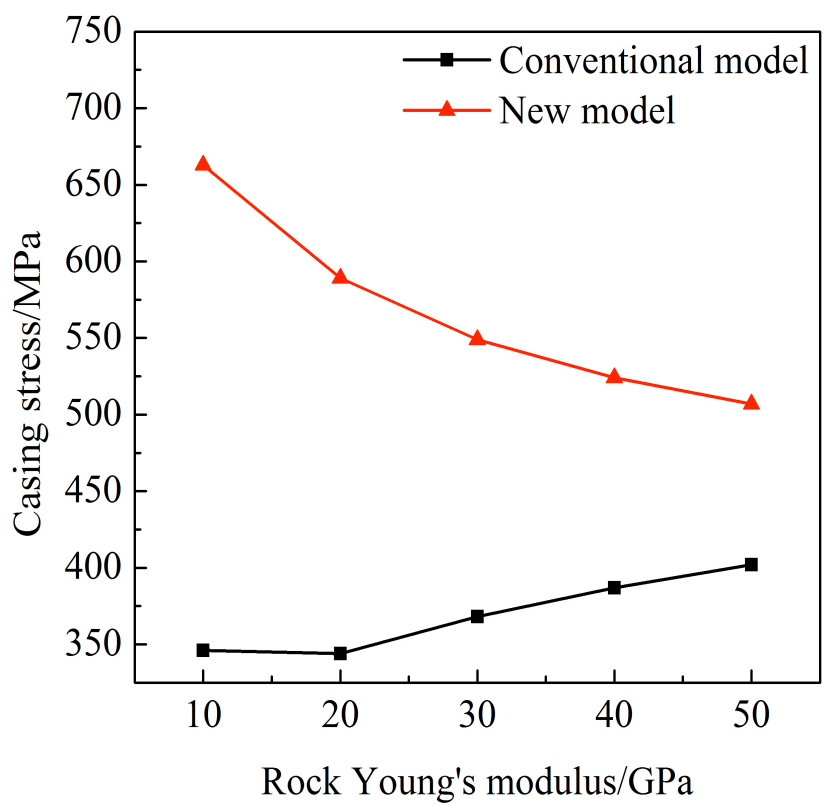

Fig. 10. Stress of perforated casing vs. Rock Young's modulus

Moreover, complex fracture networks form during fracturing operations of adjacent wells, as the hydraulic fractures connect the bedding planes and natural fractures in formation. Fracture networks generated in formation can decrease the overall Young's modulus of formation [25-27]. The effect of varying formation properties on the stress of perforated casing are shown in Fig. 10. As illustrated, the conventional model predicts that the stress of perforated casing falls gradually with the declines in the Young's modulus, which can be attributed to that the ability of formation to bear the in-situ stress drop due to weakening rock mass and the casing and cement sheath enduring more formation pressure. As for the staged FEM analysis, results have shown that the perforated casing stress rises with the decreasing Young's modulus. This is because the decrease of the rock Young's modulus relaxes the constraints of formation on the casing and the cement sheath, which are therefore subjected to more effects of the internal casing pressure. Given the above analysis, the conventional model may produce a wrong estimate of the practical condition, and meanwhile adjustments of perforation cluster parameters and optimization of the operation design based on the practical conditions of formation are necessities to avoid failure of the perforated casing induced by excessive stimulation of shale formation or post-frac non-uniform loading.

\subsection{Effects of cement properties on the stress of perforated casing}

The cement sheath is an important barrier to protect the casing and maintain the wellbore integrity. It is also an easyto-control factor, in view of practical operations. Therefore, properties of the cement have significant impacts on the perforated casing stress [28]. The evolutionary pattern of the stress of perforated casing with the Young's modulus of cement is shown in Fig. 11. Analyses based on the two models are in agreement about that the perforated casing stress slowly declines with the growth of the cement Young's modulus. According to field situations, the cement Young's modulus ranging from $30 \mathrm{GPa}$ to $45 \mathrm{GPa}$ is the most appropriate, so as to ensure the perforated casing safety with reference to its strength. It is notable that with a cement Young's modulus of $10 \mathrm{GPa}$, the perforated casing stress forecasted on the basis of the conventional model is exceedingly lower than the yield strength of the casing while the result of the new model has approached that. This observation demonstrates the tremendous significance of a perforated casing stress model as well as appropriate values of the cement Young's modulus to the forecast of the perforated casing stress, the resultant improvement on the underground stresses state of the perforated casing and reduction of the odds of the perforated casing failure.

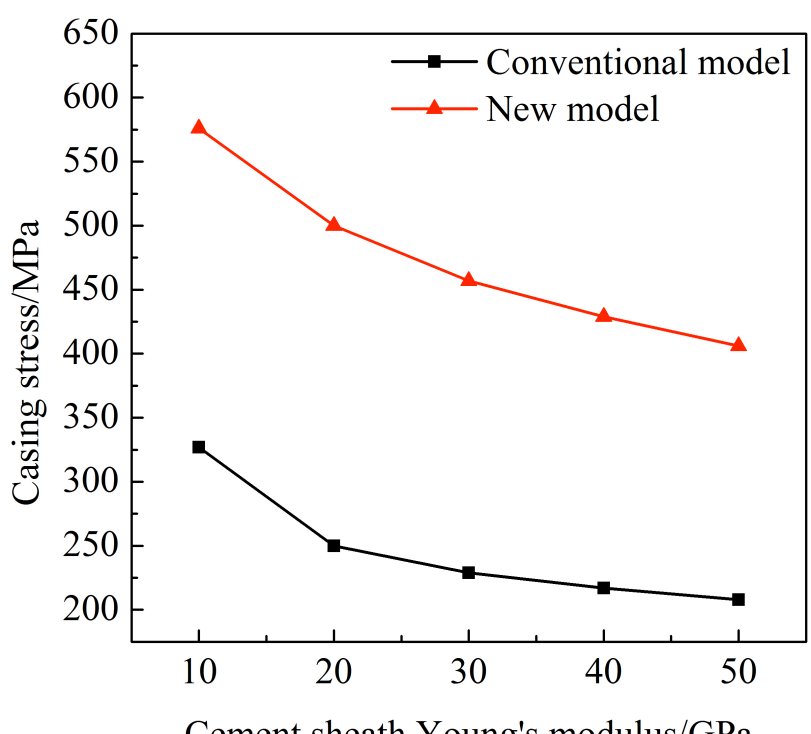

Cement sheath Young's modulus/GPa

Fig. 11. Stress of perforated casing vs. Cement sheath Young's modulus 


\subsection{Effect of internal pressure variation on the stress of} perforated casing

Simulations of changes in the stress of perforated casing with the internal casing pressure based on the conventional and new models are shown in Fig. 12. It can be seen that the predicted stress variation tendencies are the same. The perforated casing stress grows, as the internal casing pressure increases. It is also found that under circumstances of internally pressurizing the casing, the stress of perforated casing in the conventional model is still far less than that the approach taking the practical operation process into consideration. The conventional model implies that the perforated casing is still safe when the internal casing pressure reaches $110 \mathrm{MPa}$, and yet the stress of perforated casing based on the new model has reached the yield strength.

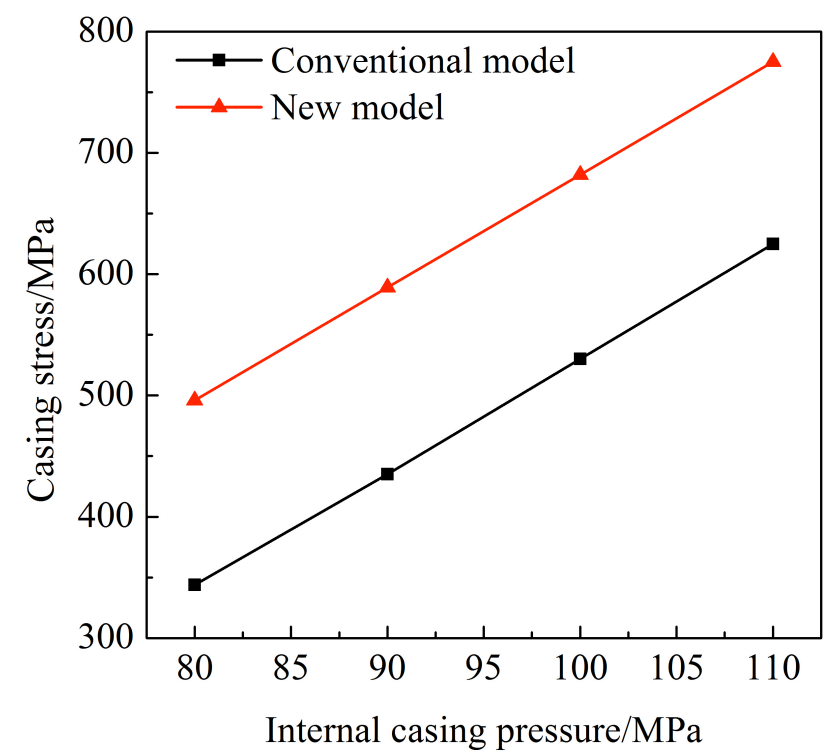

Fig. 12. Stress of perforated casing vs. Internal casing pressure

\subsection{Casing study}

In the field operation, it is believed that the casing failure during fracturing can be effectively avoided, provided the casing has sufficiently high collapse resistance. However, in fact, the casing failure happens to the perforated interval of many shale gas wells during fracturing, in some part of Sichuan Province, China. This is because inaccurate mechanical models may lead to inaccurate estimations of the perforated casing stress, which in turn, affects the determination of subsequent operation parameters.

This case study targeted a horizontal well in the Changning-Weiyuan shale gas district, Sichuan, China. This well, fractured in the first quarter of 2014, has a vertical depth of $3065 \mathrm{~m}$ and a horizontal section of $810 \mathrm{~m}$. The yield strength of the N80 casing is $551 \mathrm{MPa}$. Shaped charges were used for perforation. Each fracturing stage had three $1.2 \mathrm{~m}$ long clusters. The perforation density was 10 shots/ $\mathrm{m}$, the penetration depth was $600 \mathrm{~mm}$, and the phasing angle was $180^{\circ}$. The mini-frac testing was conducted prior to the massive hydraulic fracturing. During the fracturing operation, the pump rate was $10 \mathrm{~m}^{3} / \mathrm{min}$, and the operation pressure was $71.02-100 \mathrm{MPa}$. The total fluid injection reached $1269 \mathrm{~m}^{3}$, while the total injected proppant reached $60 \mathrm{t}$. The frictional resistance in the perforation tunnels was $15 \mathrm{MPa}$. For the third stage of fracturing, the maximum operation pressure was $100 \mathrm{MPa}$. The average
Young's modulus of the shale formation is $36 \mathrm{GPa}$, and the Poisson's ratio averages 0.307 . In terms of the in-situ stress, the vertical stress is $30 \mathrm{MPa}$, and the maximum and minimum horizontal principal stresses are $40 \mathrm{MPa}$ and $30 \mathrm{MPa}$, respectively. After accomplishing the four stages of fracturing and the individual flowback operation of each fractured wellbore stage lasting 12 hours, the bridge plug milling started and slight obstructions were observed in the third perforated interval. Four casing sections in this stage were severely deformed, according to the multi-arm caliper logging (Fig. 13).

The aforementioned two perforated casing models calculate the stress of perforated casing in the fracturing stage. In the calculation, the internal casing pressure was set at $100 \mathrm{MPa}$, the injection time at 1.5 hours and the formation as anisotropic elastic material. Results are shown in Figures 14, 15 and 16. After 1.5 hours of fluid injection, the minimum wellbore temperature decreases to $12^{\circ} \mathrm{C}$. The conventional model demonstrates that the stress of perforated casing is $531 \mathrm{MPa}$ during the high-pressure fluid injection. This value is lower than the yield strength of $551 \mathrm{MPa}$, which indicates no failure of the casing in the perforated interval and hence is inconsistent with the field observation. The predicted stress based on the new model is $775 \mathrm{MPa}$, which suggests the yield failure of perforated casing. The results of the new model relatively agree with the actual situation.

Effects of operation parameters and the cementing quality on the stress of perforated casing are shown in Table 3. Increasing the injected fluid temperature by $40^{\circ} \mathrm{C}$ leads to a reduction of about $40 \mathrm{MPa}$ in the stress of perforated casing. The Young's modulus of the cement greatly affects the stress of perforated casing. By raising the cement Young's modulus to $45 \mathrm{GPa}$ or so, the stress of perforated casing maintains at below the yield strength and thus the following operations can proceed.

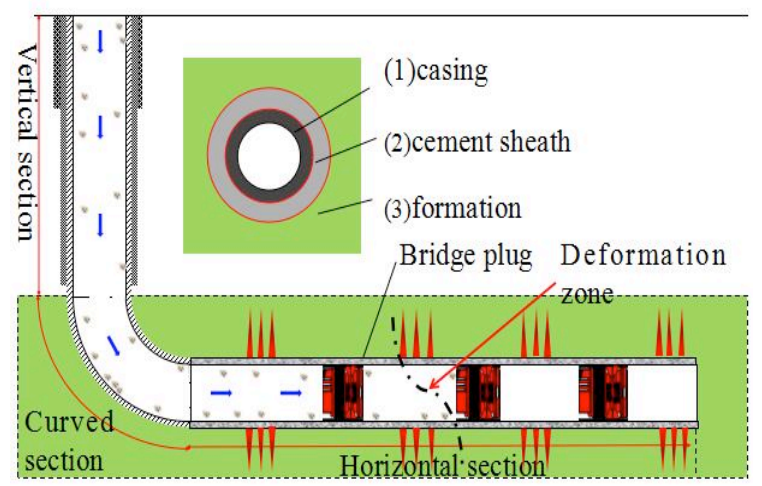

Fig. 13. Schematic diagrams of the fracturing operation in the horizontal well

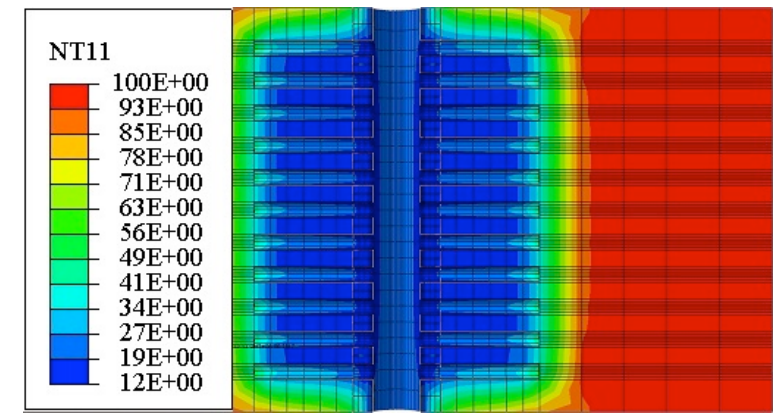

Fig. 14. Wellbore temperature distribution (after the 1.5-hour fluid injection) 


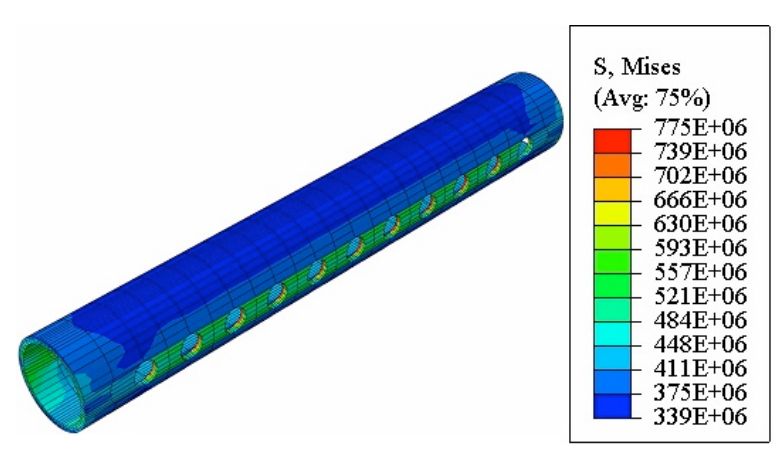

Fig. 15. Stress distribution of the perforated casing based on the new model

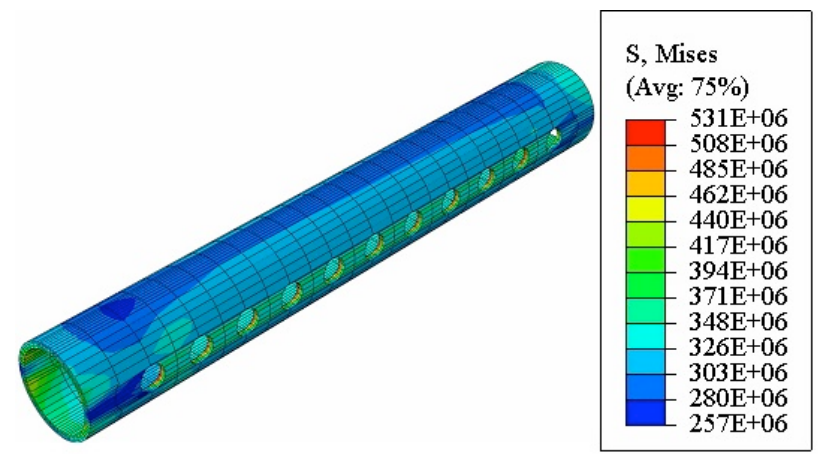

Fig. 16. Stress distribution of the perforated casing based on the conventional model

Table 3. Operation parameter optimization

\begin{tabular}{|c|c|c|c|c|c|}
\hline $\begin{array}{l}\text { Casing Injected Fluid } \\
\text { Stress } \\
\text { Temperature } \\
\text { MPa }\end{array}$ & 0 & 10 & 20 & 30 & 40 \\
$\begin{array}{l}\text { Cement } \\
\text { Young's } \\
\text { modulus/ GPa }\end{array}$ & & & & & \\
\hline 9 & 775 & 764 & 753 & 742 & 731 \\
\hline 30 & 643 & 631 & 619 & 607 & 576 \\
\hline 40 & 605 & 593 & 582 & 571 & 560 \\
\hline 45 & 589 & 577 & 566 & 555 & 544 \\
\hline 50 & 574 & 563 & 552 & 541 & 530 \\
\hline
\end{tabular}

\section{Conclusions}

In order to accurately predict the casing stress in the perforated interval during the hydraulic fracturing of shale gas wells, this study established the FEM analysis model of the perforated casing in the anisotropic formation, on the basis of the staged FEM. The variation regularity of the stress of perforated casing with temperature drop, pump pressure, and fracturing mechanical environment during the multi-stage fracturing have been analyzed. Conclusions of this study are listed below:

1) The FEM perforated casing stress model concerning shale formation, developed on the basis of the staged FEM, is capable of accurately calculating the perforated casing stress in shale formation, and well capturing the stress variation of the perforated casing during fracturing.

2) The volume hydraulic fracturing can cause excessive temperature changes in the casing and cement sheath. By increasing the temperature of the fracturing fluid and controlling the pump rate, the bottom hole temperature drop decreased, which favorably offsets the effects of thermal stress on the perforated casing of shale gas wells.

3) The reduction in internal casing pressure during operation can significantly lower the growth of stress of perforated casing induced by the decreasing Young's modulus of formation.

4) In view of the field operation, appropriate increases in the cement Young's modulus and improvement of the cementing quality can greatly reduce the odds of collapse of perforated casing.

This study comprehensively considered the stress variation of the perforated casing during drilling, completion, and fracturing, realistically reflecting the mechanical response characteristics of the perforated casing during the multi-stage hydraulic fracturing, and hence providing theoretical foundations for the operation parameter optimization in the development of shale reservoirs. However, given the insufficient data with regard to the stimulation volume of naturally fractured shale formation in the multi-stage fracturing and difficulties in real-time surveillance of downhole pressures and temperature, certain errors may exist between model parameters and practical situations. Hence, characterizing mechanical parameter with the help of the fracturing monitoring data and accurately capturing the underground temperature changes and stress fields by improving relevant mathematical models in future studies will greatly help in understanding the regular variation of stress of perforated casing during the multi-stage fracturing in shale formation.

\section{Acknowledgements}

The study was supported by the Key Program of the National Natural Science Foundation of China (5133400).

This is an Open Access article distributed under the terms of the Creative Commons Attribution Licence

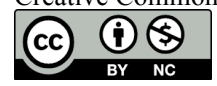

\section{References}

1. Qi W U, Yun X U, Wang X, et al., "Volume fracturing technology of unconventional reservoirs: Connotation, optimization design and implementation". Petroleum Exploration and Development, 39(3), 2012, pp.377-384.

2. Xue C., "Technical Advance and Development Proposals of Shale Gas Fracturing”. Petroleum Drilling Techniques, 39(3), 2011, pp.2429.

3. Tian Zhonglan, Shi Lin, Qiao Lei., "Research of and Countermeasure for Wellbore Integrity of Shale Gas Horizontal Well”. Natural Gas Industry, 35(9), 2015, pp.70-76.

4. Dai Qiang., "Analaysis of Production Casing Damage Reasons during Testing and Completion of Shale Gas Well". Drilling Production Technology, 38(3), 2015, pp.22-25.
5. Guo T, Zhang S, Pan L., "Numerical Simulation Study of Hydraulic Fracture Initiation for Perforated Horizontal Well in Shale Play". Chinese Journal of Rock Mechanics and Engineering, 34, 2015, pp.2721-2731.

6. Yang Shanhong., "Study of Crustal Stress Tesing and Regional Well Casing Damage Monitoring based on Fibre Sensing". Doctor thesis of Harbin Institute of Technology, 2013.

7. Zhang Shunping, Zhang Sen, Tan Yi, et al., "Anti-channeling High Density Cement Slurry Technology for Horizontal Shale Gas Well in Weiyuan". Drilling Fluid and Completion Fluid, 33(1), 2016, pp.6367. 
8. Tang B S, Chengdu, Lian Z, et al., "Theoretical Analysis of Collapsing Strength of the Perforated Casing". China Petroleum Machinery, 32(12), 2004, pp.11-13.

9. Liu Z P, Wang H W, Yan X Z., "Analysis of Casing Strength after Perforation Using Plasto-Elasticity Theory". Petroleum Drilling Techniques, 35(2), 2007, pp.31-35.

10. City D, Yan T, Li Z., "Influence of Perforation on Casing Strength". China Petroleum Machinery, 28(5), 2000, pp.42-45.

11. Ding Zupeng, Luo Yanyan, Han Bin, Deng Caifeng., "Influence of Perforating on Casing Collapsing Strength and Its Test". Drilling and Production Technology, 39(4), 2016, pp.15-18.

12. Guo Y, Blanford M, Candella J D., "Evaluating the Risk of Casing Failure Due To High-Density Perforation: A 3D FEM Case Study from a Deep Water Reservoir, GoM". In: Proceedings of the Annual Technical Conference and Exhibition, Amsterdam, Netherlands: Society of Petroleum Engineers, 2014, pp.2-15.

13. Yang B, Wei L I, Chen S, et al., "Finite Element Analysis of Compressed Volume Factor in Perforated Casing High Stress Area". Oil Field Equipment, 44(4), 2015, pp.32-35.

14. Mao-Hua L I, Shou-Yu X U, Niu W D., "Analysis and Calculation of Casing Mechanics Performance of Perforation Cement Hoop". Petroleum Geology and Oilfield Development in Daqing, 27(1), 2008, pp.106-109.

15. Yang Bing, Lian Zhanghua, Liu Jingchao., "Finite element analysis of residual strength of perforating casing"' West China Exploration Engineering, 18(8), 2006, pp.193-195.

16. Wang Z, Wang B, Zhang S., "Effects of Non-uniform Loads on Collapse Strength of High-density Perforated Casing". Natural Gas Industry, 26(10), 2006, pp.83-85.

17. Qiu X L, Yue X J, Shuai W U., "Thermal Stress Simulation of Perforated Casing in the Prossess of Producting Heavy Oil by Injection Steam". Science Technology and Engineering, 12(27), 2012, pp.6904-6907.

18. King, G.E., "The Effect of High-Density Perforating on the Mechanical Crush Resistance of Casing”. In: Proceedings of the SPE Production Operations Symposium, Oklahoma City, USA: Society of Petroleum Engineers, 1989, pp.215-221.
19. C Hair, B Schwind., "Evaulation and Design Optimization of Perforated Casing". In: Proceedings of the Offshore Technology Conference, Houston, USA: Society of Petroleum Engineers, 1993, pp.793-802.

20. Godfrey W K, Methven N E., "Casing Damage Caused by Jet Perforating". In: Proceedings of the Fall Meeting of the Society of Petroleum Engineers of AIME, Houston, USA: Society of Petroleum Engineers, 1970, pp.2-12.

21. LI Yumei, LIU Gonghui, LI Jun, YU Liwei, et al., "Numerical Analysis of Fracturing Initiation based on Anisotropic Shale". Faultblock Oil and Gas Field, 23(3), 2016, pp.380-385.

22. Batugin S A, Nirenburg R K., "Approximate Relation between the Elastic Constants of Anisotropic Rocks and the Anisotropy Parameters". Journal of Mining Science, 8(1), 1972, pp.5-9.

23. Mengbo Li, Gonghui Liu, Jun Li, Tao Zhang, Miao He., "Thermal performance analysis of drilling horizontal wells in high temperature formations". Applied Thermal Engineering, 78(3), 2015, pp.217-227.

24. Ge Weifeng, Chen Mian, Zhang Fei, Jin Yan., "Effects of Reservoir Pressure Drop on Equivalent Stress on Casings of the Reservoir and the Upper Salt Layer in High Dipping Formation". Science Technology and Engineering, 15(14), 2015, pp.39-42.

25. Yu Hao, Lian Zhanghua, Lin Tiejun., "Finite Element Analysis of Failure Mechanism of Casing during Shale Gas Fracturing”. China Petroleum Machinery, 42(8), 2014, pp.84-88.

26. Tiejun Lin, Hao Yu, Zhanghua Lian, Yonggang Yi, Qiang Zhang., "Numerical Simulation of the Influence of Stimulated Reservoir Volume on in-situ Stress Field". Journal of Natural Gas Science and Engineering, 2016, 36, pp.1228-1238.

27. Lian Z, Yu H, Lin T, et al., "A Study on Casing Deformation Failure during Multistage Hydraulic Fracturing for the Stimulated Reservoir Volume of Horizontal Shale Wells". Journal of Natural Gas Science and Engineering, 2015, 23, pp.538-546.

28. Zhang Zhi, Xu Hongling, Liu Zhiwei., "The Effect of Sustained Casing Pressure on the Mechanical Integrity of Cement Sheath in Gas Wells". Journal of Southwest Petroleum University (Science and Technology Edition), 38(2), 2016, pp.155-161. 